\title{
RESEARCH ON FACTORS ANALYSIS MODEL OF DUALISTIC SOIL SALINIZATION SENSITIVITY IN TYPICAL NORTHWESTERN ARID AREA
}

\author{
Tao SUN ${ }^{\mathrm{a}, ~}{ }^{*}$, Haiying DENG ${ }^{\mathrm{b}}$, Shibing Pan ${ }^{\mathrm{a}}$, Shifeng Huang ${ }^{\mathrm{a}}$ \\ ${ }^{a}$ Remote Sensing Center, China Inst. of Water Resources and Hydropower Research, Beijing, \\ China-(sunt,pansb,huangsf)@iwhr.com

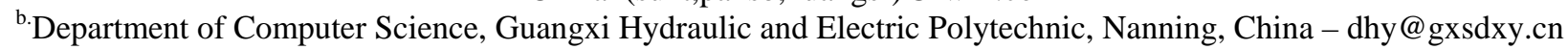

KEY WORDS: Soil Secondary Salinization; Affective Factors; Sensitivity Analysis; RS and GIS; Genetic Artificial Neural Network; Shule River Watershed

\begin{abstract}
:
Soil secondary salinization is one of the typical ecological side effects caused by land and water resources development in northwestern arid China. Factors that affect the occurrences and developments of salinization come from both natural conditions and human activities. Research on the mechanisms of salinization, build dynamic prediction model of salt accumulation and analyze sensitivities to different factors would supply effective references to the prediction and prevention of soil salinization. It is well known that related factors are always intertexture together, affecting each other, which result in multivariable, nonlinear and overall influences that work on the process of soil salinization. Artificial intelligence technologies may play important role in this domain. In this paper, genetic artificial neural network based model is built to simulate and evaluate soil salt accumulation and sensitivity of soil salinization. Example is taken from the Shule River watershed, typical arid area in northwestern China. Basic data of June 2000 are prepared depending on GIS and Remote Sensing. Precipitations, evaporations, groundwater levels, groundwater chemical analysis data and soil accumulation data are achieved and interpolated in the research area. Slope of the land are derived from DEM, MODIS images are used in the process of dealing with land use information. At the same time, landform and soil type are considered in model building. Soil salt accumulation is analyzed with its 8 influenced factors with verified models. Results showing that groundwater TDS is the most sensitive factor followed by groundwater level, evaporation and the depth of upper bed of clay. In most cases clay layers play key roles in soil salt accumulation, precipitation and slop have similar sensitivities. Results would have better research and application value in arid areas of northwestern China.
\end{abstract}

\section{INTRODUCTION}

\subsection{Soil Salinization}

As one of the typical ecological side effects caused by water and land resources development in western arid area, China, soil salinization will result in, in one hand, the death of land surface plants. In the other hand, lands without the protection of plants will turn into deserts ultimately [1,2]. Soil salinization is regarded as the third cause of desertification with main researches focus on the causes of formation, mechanism and driving factors so as to analyze and predict its development [3]. Sensitivity analysis which belongs to the domain of ecoenvironmental evaluation, indicates the probability of soil salinization under the effects of natural changes and human activities. Nowadays, predominant researches on sensitivity analysis are centralized on acid rain [4].

Regular evaluation of soil sensitivity is under natural or static conditions, showing the salinization potential of soils. The higher the sensitivity, the easier the soil will be salinized. On such cases, only simple interferences are concerned, unitary soil salinization sensitivity is considered. However, the one under the common effects of both natural condition and human activity is defined as dualistic sensitivity. Research on factors affect soil salt accumulation, build dynamic salt accumulation models so as to analyze sensitivity degree to different influence factors are key to the prediction, prevention and cure of soil salinization.

\subsection{Model Building Analysis}

Unitary sensitivity analysis of soil salinization is usually processed in static state referenced with the Temporary Regulation of Ecological Function Area Division Techniques (Published by Environment Agency of China, 2002). With the aids of GIS platform, soil salinization sensitivity is divided into 5 levels, namely ultra sensitivity, high sensitivity, medium sensitivity, less sensitivity and non sensitivity which are used to identify types and distribution characteristics related with salinization.

One thing worth mention is that the occurrence and development of the soil salinization in arid western China is influenced under dualistic module. Affected factors come from both natural condition and human activities. Climate, land form, soil type, groundwater dynamic changes, etc. are the main influences and irrigation schedules and unreasonable land use may also cause the secondary salinization of soils. Generally speaking, soil salinization shows close relations with groundwater. The shallower the groundwater level, the more serious the degree of soil salinization because of the stronger evaporation and high TDS of groundwater. But, the theory may be different even if the groundwater hydrological characteristics

\footnotetext{
* Tao Sun, Remote Sensing Center,China Institute of Water Resources and Hydropower Research, West Road 20\#,Chegongzhuang,Beijing,Zip code:100044,Tel: +86-10-68785410
} 
are almost identical. Reversed results between groundwater imbedded depth with soil accumulation level are encountered at times. The reason lies in the interlaced effects of correlated factors. Researches applied with multi-variant non-linear models are considered in this paper to reflect above issues.

\section{TYPICAL RESEARCH AREA}

Arid areas of western China lie to the north of $35^{\circ} \mathrm{N}$ and to the west of $106^{\circ} \mathrm{E}$, including inland areas in Xinjiang, Gansu Hexi corridor and western of Helan mountain in Inner Mongolia, total area accounts for about $24.5 \%$ of the whole China. Annual precipitations of these regions are below $150 \mathrm{~mm}$, they are one of the driest areas in the world [5]. Among which the Hexi corridor, famous for its little precipitation and water shortage, is fragile in eco-environments. The Shule river basin, in the ultimate west of the corridor, is selected as the typical arid areas in this research. Regional salinization characterized as strong surface accumulation and re-conglomeration under the complex function of climatic factors, geological and hydrogeological conditions, landform, physiognomy, vegetations and human beings. At the same time, the existence of underlying clay and its depth play as a double sword in the process of soil salinization. Previous study shows that groundwater level (depth), TDS, precipitation, evaporation, slope gradient, soil texture, land use and underlying clay are the main influencing factors of soil salinization in this area.

\section{METHODOLOGY AND DATA ACQUIREMENT}

\subsection{Methodology}

Although it seems easier to understand the relations between groundwater level (or TDS) with soil salinization, there is no evidences that there are certain obvious and linear equations which can be used to describe well their relations. Considering the complication of soil salinization and their driving factors, the author attempts using the artificial intelligence technique, Genetic Algorithm and Back error Propagation Artificial Neural Network (GABPANN), to build dualistic soil salinization models. Artificial Neural Network (ANN) and Genetic Algorithm (GA) are two branches of artificial intelligence, which are widely used in dealing with multi-dimensional, complicated and non-linear problems [6]. ANN simulates the signal input, process and output of biologic neural cell while GA, based on the evolutionism of Darwin and genetic theory of Mendel, makes close imitations of biology and obey the rule of "survival of the fittest" to obtain optimal solution of a problem.

Back error Propagation Artificial Neural Network (BPANN) has the advantage of self-organization, self-study, selfadaptation as well as robust input, output and nonlinear mapping abilities. Though simple and easy to be implemented, BPANN always converged at local point instead of global solution owing to its gradient-descending algorithm besides its uncertain network structure. Furthermore, in dealing with complicated problems as those of eco-environmental evaluations, BPANN is rather a time-consuming work. On the contrary, GA shows better performance in seeking optimal solution regardless of its weak mapping ability and limited factors could be considered [7].
GABPANN combines BPANN and GA, making use of the strongpoint of both algorithms, in the establishing of soil salt sensitivity evaluation model. The key procedures are separate into 8 steps (see Figure 1).

a) fix the topological structure of BP network, use float data type as weighting code and generate original seeds group;

b) construct BP network according to different seed;

c) calculate fitness in term of specific criteria;

d) seek proper seeds depending on fitness value of single group;

e) obtain new groups after the process of cross and mutation;

f) go to the second step until the results satisfied, achieve a set of optimal weights;

g) train in ordinary BP network until it converged to given value;

h) predict and evaluate with trained network

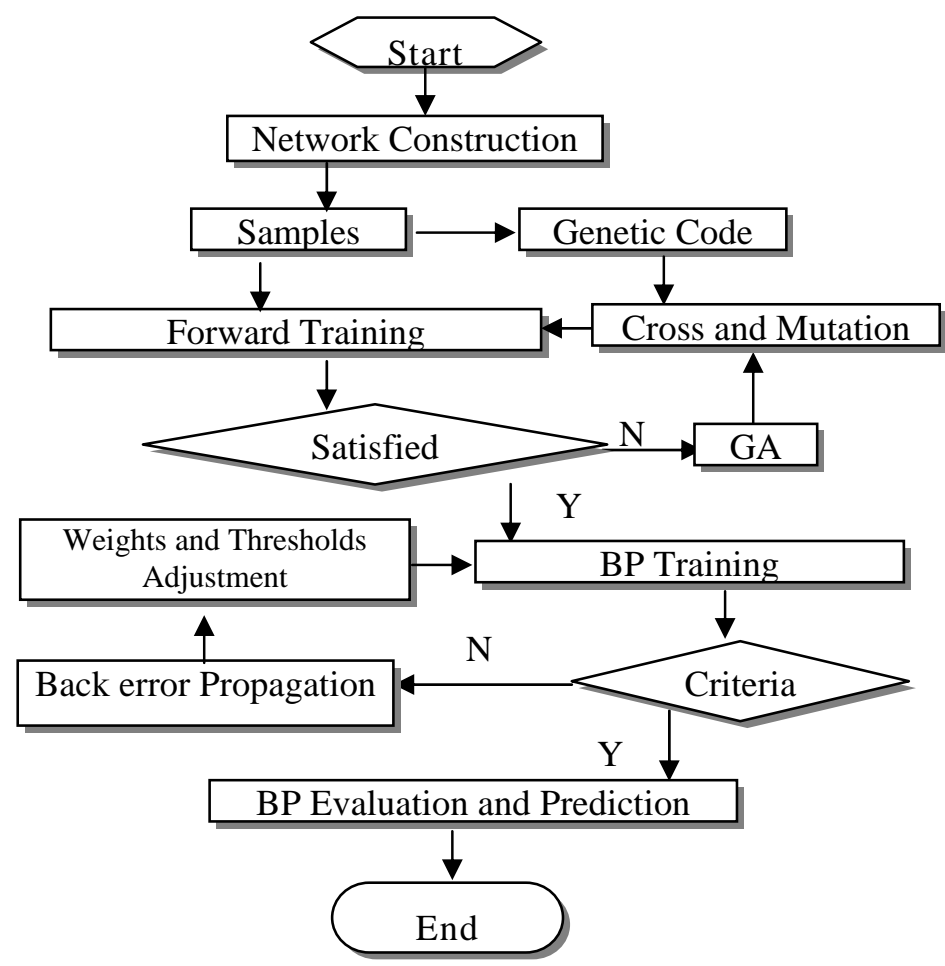

Figure 1. Flow chart showing weight oriented GABPANN

\subsection{Data Acquirement}

Basic data used partly are those observed directly in July 2000, for example, groundwater levels, TDS, underlying depth of the clay, precipitation, evaporation, and soil salt accumulation data. Others are achieved indirectly based on GIS or remote sensing techniques, which play important role in data obtaining process. Slope gradients are calculated from DEM of the area, land use information are extracted through MODIS images. Soil texture map, together with that of landform is used to describe soil types. Some data of the eight driving factors are interpolated so as to in accordance with those of soil salt contents.

\section{ANALYSIS AND DISCUSSION}

Input layer of the network have eight nodes, each represent precipitation (P), evaporation (E), buried depth of groundwater (WD), TDS (M), gradient of slope (S), soil texture (B), land 
use (N) and underlying depth of clay (CD) respectively. Output layer has one node, i.e. soil salt content (Ss), and two hidden layers with 10 and 4 nodes each. So the structure of the network is $8: 10: 4: 1$. Seeds group $(\mathrm{m})$ is set to 60 , cross probability (Pc) 0.7 , mutation probability $(\mathrm{Pm}) 0.05$ and evolution generation 200. To sum up, the overall structure (S) of GABPANN model showing in the form of eight parameters as:

$\mathrm{S}=(8,10,4,1,60,0.7,0.05,200)$

Activating function $f(s)$ is a variant from the base function of sigmoid.

$$
f(s)=n \frac{1-e^{-s}}{1+e^{-s}}
$$

In above equation $\mathrm{n}$, coefficient of soil salinization, has direct relation with salt content of soil. 200 is a proper value in this study. There are 124 weights and 15 threshold values for each group in conformity with the GABPANN structure. Complex as it is, float point genetic algorithm (FGA) is used to optimize the weights of BP network [8] (see Figure 2).

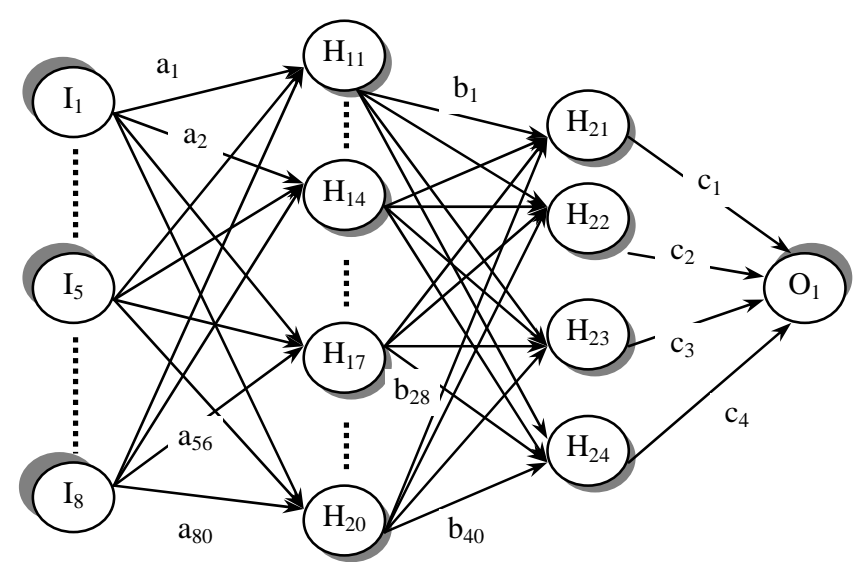

Genetic code for each initial seed

$$
\left(a_{1}, a_{2}, a_{3}, \cdots, a_{80}, b_{1}, b_{2}, b_{3}, \cdots, b_{40}, c_{1}, c_{2}, c_{3}, c_{4}\right)
$$

Figure 2. Schematic map of FGA genetic code

GA aims at seeking the maximum value of a function, so corresponding fitness function $f$ would be set as $f=1 / \sum_{i=1}^{n} e_{i}^{2}$ where $e_{i}$ is calculated in the BP network. C language is used to compile the calculating programme.268 samples are selected in the research area, in which 168 are used to train the network and the left to verify accuracy with the trained model. Iteration errors are within given range with single errors fall between 0.12 and 8.26. Two indexes, verification ratio $\mathrm{C}$ and minor error frequency $\mathrm{p}$, are used to evaluate the credibility of the model. Results showing that the whole model accuracy reaches to "Fine" level, meets the

\begin{tabular}{|c|c|c|c|c|c|c|c|}
\hline Sample & $\begin{array}{c}\text { Maximun } \\
\text { Error } \\
\text { (g/kg) }\end{array}$ & $\begin{array}{l}\text { Minimun } \\
\text { Error } \\
(\mathrm{g} / \mathrm{kg})\end{array}$ & $\begin{array}{c}\text { Mean } \\
\text { Error } \\
(\%)\end{array}$ & $\begin{array}{l}\text { Points in } \\
95 \% \\
\text { confidenc } \\
\text { e interval }\end{array}$ & $\mathrm{C}$ & $\mathrm{p}$ & $\begin{array}{c}\text { Accurate } \\
\text { level }\end{array}$ \\
\hline Training & 5.48 & 0.12 & 2.51 & 153 & 0.32 & 0.96 & $\begin{array}{c}\text { Excellen } \\
\mathrm{t}\end{array}$ \\
\hline $\begin{array}{c}\text { Verifyin } \\
\text { g }\end{array}$ & 8.26 & 0.24 & 3.26 & 86 & 0.37 & 0.87 & Fine \\
\hline Overall & 8.26 & 0.12 & 2.94 & 239 & 0.35 & 0.92 & Fine \\
\hline
\end{tabular}
demand of the requirement (see Table 1).

Table 1. Error analysis and accuracy evaluation of GABPANN model

Accordingly, the weights matrix can be used as identifying factors in the prediction of soil salt salinization. Adjusting WD, M, E, P, S, CD in the range of $20 \%$ to their original values and keeping $\mathrm{B}, \mathrm{N}$ unchanged, model results will reflect the sensitivities of each factors. [9] (see Figure 3)
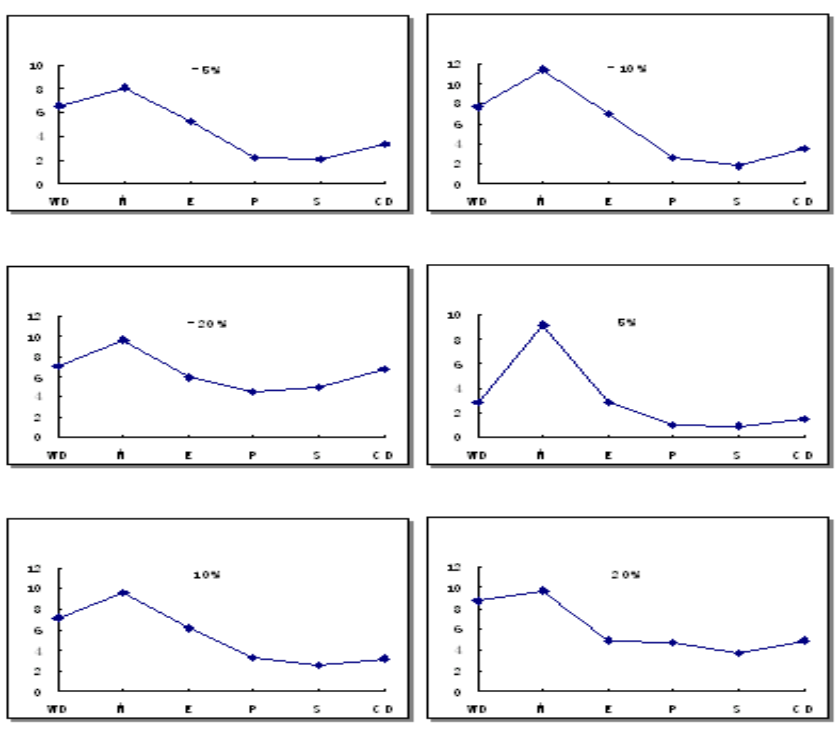

Figure 3 Relation of salinization change with affecting factors

Generally speaking, soil accumulates salt with the rise of groundwater level, the increase of TDS, evaporation and with the decrease of slope gradient, precipitation and underlying clays. Considering concrete factors, fig.3, salinization changes under different variation of affecting factors, indicates that TDS has the strong influencing ability among the eight factors. It is the most sensitive factor, followed by groundwater level, evaporation. The existence of underlying clay also play important role in soil salt accumulation. In most cases, depth of underlying clay affects more violently than those of precipitation and slope gradient. 


\section{CONCLUSION}

Salinization is influenced by dual modules, natural conditions and human activities in northern western arid areas, China. Sensitivity analysis of related factors is essential to the prediction, prevention and cure of soil salinization. Research in typical arid area with 268 samples, with the aids of GABPANN prediction model, will provide some proofs for further study. Network parameters optimization of BP with GA, not only quicken the speed of convergence but also optimize in the overall domain. GABPANN connects with FGA, avoiding traditional code type of binary, do improve the efficiency of the model and will be a trend in future research.

\section{REFERENCES}

[1] Can Tang, Hui Meng, Desertification analysis in Hexi corridor, The Chinese Journal of Geological Hazard and Control, 1990, 10(4).

[2] UNCOD.Desertification:its causes and consequences, Oxford Pergamon Press,1977.

[3] Shigong Zhang, Jianjun Qiu, Hua Zhang, Resources of soil salinization and its prediction and cure in China, Journal of China Agricultural Resources and Regional Planning, 2000,21(1).52 56.

[4] Tao F, Feng Z, Terrestrial ecosystem sensitivity to acid deposition in South China. Air,Water and Soil Pollution, 1999.

[5] Yafeng Shi, Affects of climate changes to water resources in northwest China, Publishing House of Shandong Science and Technology,1995.17 25.
[6] Shuyan Zheng, Zhanbin Li, Xian Li, Artificial Neural Network in the prediction of groundwater water variation, Northwest Water Resources \& Water Engineering, 2002,13(2).14 16.

[7] Jiancheng Luo, Chenghu Zhou, Yan Yang, Research on classification models of remote sensing images and methods of knowledge integration, Journal of Remote Sensing, 2001,5(2).122 129.

[8] Tao Sun, Shibing Pan, Yongjun Li, Artificial Neural Network in the application of groundwater quality classification, Hydrogeology and Engineering Geology, 2004,31,(3).58 62,1995.17 25.

[9] Wei Wang,Principle of Artificial Neural Network, Beijing University of Aeronautics and Astronautics Press, 1995.

\section{ACKNOWLEDGEMENT}

The research is funded by China inst. of Water Resources and Hydropower Research and Department of Computer Science, Guangxi Hydraulic and Electric Polytechnic. This research is also supported by the National Natural Science Foundation Committee (NSFC). Especially thanks to all the program members. 